\title{
Pharmacist's Knowledge and Behaviors Toward Pharmacovigilance and Adverse Drug Reactions Reporting Process in Türkiye
}

\author{
(1D Aslınur ALBAYRAK1,2*, (1) Bensu KARAHALIL ${ }^{3}$ \\ ${ }^{1}$ Gazi University, Faculty of Pharmacy, Department of Clinical Pharmacy, Ankara, Türkiye \\ 2Suleyman Demirel University, Faculty of Pharmacy, Department of Clinical Pharmacy, Isparta, Türkiye \\ ${ }^{3}$ Gazi University, Faculty of Pharmacy, Department of Pharmaceutical Toxicology, Ankara, Türkiye
}

\begin{abstract}
Objectives: Adverse drug reactions (ADRs) increase patient-related morbidity and mortality. Additionally, it is an important public health problem associated with prolonged hospital stay and increasing economic burden. Pharmacovigilance is central to reducing ADRs, so the development and growth of this science is critical to effective and safe clinical practice. The aim of the study was to evaluate the knowledge and behaviors of pharmacists toward pharmacovigilance and spontaneous ADR notifications in Türkiye.

Materials and Methods: The online questionnaire method was used with the pharmacists, whose prior consent was obtained to participate in the study. The survey was uploaded onto Google form. The survey link was distributed electronically to the eligible participants via social media channels. The knowledge of pharmacovigilance practice, ADR reporting compliance rates, reasons for not reporting ADR, and perceptions of the Turkish pharmacists on pharmacovigilance practice were evaluated.

Results: Four hundred six pharmacists (45\%) agreed to participate in the study, $81.8 \%$ of whose correctly defined correctly defined the term pharmacovigilance. $91.6 \%$ knew the name of the Turkish Pharmacovigilance Center. Clinical and hospital pharmacists were found to have a more adequate knowledge than community pharmacists ( $p<0.05$ ). 18.7\% of pharmacists stated that they had previously reported ADRs. Most of the pharmacists stated that the most important reason for not reporting ADRs was not knowing how and where spontaneous reporting should be done, a single spontaneous reporting would not make a difference and the report would generate extra work.

Conclusion: These results showed that Turkish pharmacists had adequate knowledge about the concept of pharmacovigilance and the spontaneous ADR reporting system. However, they had little experience in reporting. Training programs should continue to increase the knowledge and reporting experience of pharmacists about the reporting process and requirements.
\end{abstract}

Key words: Adverse drug reaction reporting system, pharmacists, pharmacovigilance, knowledge, behavior

\section{INTRODUCTION}

Adverse drug reactions (ADRs) increase patient-related morbidity and mortality. Additionally, it is an important public health problem associated with prolonged hospital stay and increasing economic burden., ${ }^{1}$ Pharmacovigilance is central to reducing ADRs, so the development and growth of this science is critical to effective and safe clinical practice. The World Health Organization defines pharmacovigilance as "science and activities related to the detection, evaluation, understanding, and prevention of side effects or other possible drug-related problems". 3

Healthcare professionals are central to providing a robust pharmacovigilance system. Consumers are more likely to report ADRs to their physicians or pharmacists than to the pharmaceutical industry.,5 All health system sectors should be included in the reporting process. ${ }^{6}$ Pharmaceutical care involves assessing these risks on a patient-by-patient basis by "identifying and solving (or preventing)" drug therapy problems. 
Therefore, pharmacists play an important role in safe drug use and should be aware of this. ${ }^{7}$ Unfortunately, the rate of selfreporting of ADRs by healthcare professionals around the world is extremely low, as it is not a mandatory requirement in most countries. ${ }^{4,5}$ After the thalidomide disaster in the 1960s, many countries developed their national pharmacovigilance centers. ${ }^{8}$ "Türkiye Adverse Drug Effects Monitoring and Evaluation Center" is Türkiye's first national pharmacovigilance center, which was established in 1985. In 2005, its name was changed to "Turkish Pharmacovigilance Center" (TUFAM). According to the regulations, all healthcare professionals have to report a serious and unexpected ADR to TUFAM within 15 days, either directly by post, fax, or e-mail, or through the pharmacovigilance contact point in the healthcare institutions where they work. ${ }^{9}$ Many studies from other countries show the role and attitudes of pharmacists in ADR reporting.,50-13 There are a limited number of studies evaluating the knowledge and behavior of pharmacists regarding pharmacovigilance and spontaneous ADR reporting in Türkiye..$^{4}$ This study evaluates the knowledge and behaviors of pharmacists regarding pharmacovigilance systems and spontaneous ADR reporting in Türkiye.

\section{MATERIALS AND METHODS}

\section{Study design and settings}

This cross-sectional study was conducted between April $10^{\text {th }}$, and May $10^{\text {th }}, 2021$. The online questionnaire method was used with the pharmacists, whose prior consent was obtained to participate in the study. The survey was uploaded onto Google form. The first page of the survey contains information about the research subject. There was an option to either consent to or refuse participation in the survey at the end of this page. The individuals, who chose to participate, were allowed to complete the survey. The survey link was distributed electronically to the eligible participants via social media channels (Instagram, WhatsApp, and Facebook). Ethical approval for this study was obtained from the Gazi University Ethics Committee (approval number and date 2021-445/06.04.2021).

\section{Sampling technique and sample size}

An online questionnaire was applied to randomly selected community pharmacists, hospital pharmacists, and clinical pharmacists in Türkiye. Academic pharmacists working at the university and non-active pharmacists were excluded from the study.

According to the data of the Turkish Pharmacists Association, there are 37.442 pharmacists in Türkiye. The online Raosoft sample size calculator (http://www.raosoft.com/samplesize. $\mathrm{html}$ ) estimated the sample size of a minimum of 381 pharmacists to provide a $95 \%$ confidence level with a $5 \%$ margin of error, assuming $50 \%$ of pharmacists express good knowledge.

\section{Data collection}

The questionnaire items and question selection were based on previous research and interviews with senior pharmacists on this subject. A draft questionnaire was designed to be subjected to tests and examinations by community pharmacists ( $n: 10)$ and hospital pharmacists ( $n$ : 10). The survey questions were then adjusted according to the qualitative feedback provided by the respondents and the results of the internal validity measurement. Cronbach alpha score was 0.6. There were 19 questions in the study. The first 5 questions were based on the demographic information of the participants, while 6-11 questions were about knowledge and 12-18 of the questions were about behavior.

\section{Statistical analysis}

Statistical analyses of the main survey data were performed using IBM SPSS (version 24.0) with significance levels set at $p \leq 0.05$. Demographic variables and responses given to knowledge and behavior questions were analyzed using descriptive statistics. Descriptive analyses were used to represent the results as percentages and frequencies. For knowledge questions, correct answers were scored as 1, and wrong answers were scored as 0 . Six questions were calculated as 6 points and corresponded to $100 \%$. A score of more than $80 \%$ was accepted as adequate knowledge, while a total score $\leq 80 \%$ was classified as inadequate knowledge. Scoring was not done for behavior questions. Association between patients' socio-demographic characteristics and ADR knowledge was also assessed using the Pearson chi-square test.

\section{RESULTS}

The questionnaires were sent to 900 pharmacists, whereas 406 pharmacists (45\%) agreed to participate. $73.4 \%$ of the respondents were women and $51.3 \%$ of the respondents were between the ages 22-29. Community pharmacists constituted $65 \%$ of the respondents, while $21.4 \%$ were hospital pharmacists and $13.5 \%$ were clinical pharmacists. The respondents rated at $54.2 \%$ had a working period as a pharmacist in less than 5 years and $17.2 \%$ of them had a postgraduate degree. Sociodemographic characteristics of pharmacists are summarized in Table 1.

\section{Table 1. Demographic characteristics of pharmacists ( $n: 406)$}

\begin{tabular}{ll} 
Variables & $\mathrm{n}(\%)$ \\
\hline Gender & $298(73.4)$ \\
\hline Female & $108(26.6)$ \\
\hline Male & $210(51.7)$ \\
\hline Age, ranges & $82(20.2)$ \\
\hline $22-29$ & $90(22.2)$ \\
\hline $30-44$ & $24(5.9)$ \\
\hline $45-59$ & $264(65)$ \\
\hline$>60$ & $87(21.4)$ \\
\hline Work place & $55(13.5)$ \\
\hline Community pharmacist & \\
\hline Hospital pharmacist & $220(54.2)$ \\
\hline Clinical pharmacist & $186(45.8)$ \\
\hline Experience as a pharmacist & $70(17.2)$ \\
\hline$\langle 5$ years & $336(82.8)$ \\
\hline$\geq 5$ years & \\
\hline Postgraduate degree (MSc, PhD) & \\
\hline Yes & \\
\hline No & \\
\hline
\end{tabular}




\section{Knowledge}

Table 2 demonstrates the responses to questions related to knowledge. The respondents rated at $81.8 \%$ defined the term pharmacovigilance correctly, whereas $46.3 \%$ of the respondents correctly answered the location of the world pharmacovigilance center. $91.6 \%$ knew the name of Türkiye's National Pharmacovigilance Center. $79.8 \%$ of the respondents answered correctly, who could report ADRs and $83.3 \%$ knew which ADRs could be reported correctly. $70.4 \%$ of the respondents knew how to report an ADR. Table 3 shows the association with socio-demographic characteristics of patients and pharmacovigilance awareness as well as ADR knowledge and reporting of previously experienced ADRs. $57.6 \%$ of the respondents had sufficient knowledge of ADRs. The relationship of ADR information with age, gender, duration of the study, and postgraduate degree was not found to be statistically significant ( $p>0.05$ ). The relationship between the pharmacist's work area (clinical pharmacist or hospital pharmacist or community pharmacist) and the previous reporting of ADRs was significant ( $p<0.05$ ). Clinical and hospital pharmacists were found to have better knowledge levels than community pharmacists.

\section{Table 2. Knowledge of the pharmacists concerning pharmacovigilance and reporting ADRs}

\section{Questions}

What is pharmacovigilance?

Adverse drug reaction reporting

Detection, recognition, evaluation, and prevention of adverse drug reactions*

The science of evaluating the benefit/risk profile of a medicinal product

Do not know

Where is the World Pharmacovigilance Center located?

United States of America

France

United Kingdom

Sweeden*

Which institution is responsible for adverse reaction reporting and monitoring in Türkiye?

TUFAM*

The Regional Board of Pharmacists

Turkish Pharmacists Association

Do not know

Who can spontaneously report adverse drug reactions?

Doctor

Pharmacist

Dentist

Nurse

All of above*

What types of adverse drug reactions are expected to be reported?

Serious and unexpected

Not serious

Expected adverse reactions

All adverse reactions regardless of seriousness and expectedness*

Do not know

Do you know how to report adverse drug reactions?

Yes*

No

*True answer, ADRs: Adverse drug reactions, TUFAM: Turkish Pharmacovigilance Center
$58(14.3)$

$2(0.5)$

338 (83.3)

\section{n (\%)}

$$
52 \text { (12.8) }
$$

332 (81.8)

16 (3.9)

6 (1.5)

\section{4 (42.9)}

$30(7.4)$

14 (3.4)

188 (46.3)

20 (4.9)

14 (3.4)

12 (3)

70 (17.2)

324 (79.8)

8 (2)

$286(70.4)$

120 (29.6) 


\section{Behaviors}

Table 4 shows that pharmacists' behavior toward reporting ADRs. $40.4 \%$ of pharmacists stated that they did not experience ADRs in their patients at all, 39.9\% experienced them once a year, $15.8 \%$ once a month, and $3.9 \%$ once a week. Previously, 76 pharmacists (18.7\%) were found in the ADR notification.

$55.2 \%$ were serious, $31.5 \%$ were unexpected, and $5 \%$ were rare type ADRs. $99.5 \%$ of the respondents stated that it was important to report ADRs. The relationship between the pharmacist's work area (clinical pharmacist, hospital pharmacist or community pharmacist) and the previous reporting of ADRs was significant ( $p<0.05$ ). $35.6 \%$ of hospital pharmacists, $23.6 \%$ of clinical pharmacists, and $12.1 \%$ of community pharmacists, who participated in our study, declared that they had previously reported ADRs.

Some of the respondents (36.9\%) stated that the most important reason for not reporting ADRs was that they did not know how and to where spontaneous reporting should be done. $19.2 \%$ of them stated that a single spontaneous reporting would not make a difference and $18.7 \%$ stated that the report would generate extra work (Table 5). Among the factors that encourage reporting ADRs are; the reaction was serious $(31.5 \%)$, the reaction was unexpected $(22.7 \%)$, the training of healthcare professionals $(19.2 \%)$, and the reporting process was practical and easy (17.7\%) (Table 6).

\section{DISCUSSION}

The results of our study revealed that although Turkish pharmacists had sufficient pharmacovigilance and theoretical knowledge about ADRs, they showed a low rate of ADR reporting. $81.8 \%$ of the respondents correctly defined the term pharmacovigilance. This was a fairly high rate. In the study by Kopciuch et al. ${ }^{11} 73 \%$ of the respondents, $69.5 \%$ of the respondents in the study by Su et al. ${ }^{15}$, and $81.9 \%$ of the respondents in the study by Li et al. ${ }^{5}$ defined the term pharmacovigilance correctly. In the study by Suyagh et al. ${ }^{16}, 25.5 \%$ of the participants correctly defined the term pharmacovigilance. In our study, $91.6 \%$ of respondents correctly knew the institution reporting national ADRs in Türkiye, while nearly half of the respondents in the study by Kopciuch et al. ${ }^{11}$ knew this correctly in the study by Suyagh et al. ${ }^{16} 76 \%$ of the respondents declared that they did not know where to find the necessary forms for ADR reporting and $60 \%$ of the respondents did not know the national pharmacovigilance center in the study by Vigneshwaran et al. ${ }^{17}$ Toklu and Uysal ${ }^{14}$ evaluated the knowledge and attitudes of pharmacy pharmacists in Türkiye regarding ADRs in 2008.

Table 3. Association of pharmacists' demografic characteristics with pharmacovigilance awareness, knowledge of adverse drug reaction reporting

\begin{tabular}{|c|c|c|}
\hline \multirow{2}{*}{ Variables } & \multicolumn{2}{|l|}{ ADR knowledge } \\
\hline & Adequate (score $>80 \%$ ) & Inadequate (score $<80 \%$ ) \\
\hline Gender & $p>0.05$ & \\
\hline Female & $176(75.2)$ & $122(70.9)$ \\
\hline Male & $58(24.8)$ & $50(29.1)$ \\
\hline Age (years) & $p>0.05$ & \\
\hline $22-29$ & $132(56.4)$ & $78(45.3)$ \\
\hline $30-44$ & $52(22.2)$ & $30(17.4)$ \\
\hline $45-59$ & $38(16.2)$ & $52(30.2)$ \\
\hline$>60$ & $12(5.1)$ & $12(7)$ \\
\hline Work place & $p=0.01$ & \\
\hline Community pharmacist & $128(54.7)$ & $136(79.1)$ \\
\hline Hospital pharmacist & $63(26.9)$ & $24(14)$ \\
\hline Clinical pharmacist & $43(18.4)$ & $12(7)$ \\
\hline Experience as a pharmacist & $p>0.05$ & \\
\hline$\langle 5$ years & $136(58.1)$ & $84(48.8)$ \\
\hline$\geq 5$ years & $98(41.9)$ & $88(51.2)$ \\
\hline Postgraduate degree (MSc, PhD) & $p>0.05$ & \\
\hline Yes & $44(18.8)$ & $26(15.1)$ \\
\hline No & $190(81.2)$ & $146(84.9)$ \\
\hline
\end{tabular}

ADR: Adverse drug reaction 
Table 4. Pharmacists behaviors towards reporting ADRs

n (\%)

\begin{tabular}{lr} 
How often do you see ADRs in patient? & \\
\hline Once a week & 16 (3.9) \\
\hline Once a month & $64(15.8)$ \\
\hline Once a year & $162(39.9)$ \\
\hline Never & $164(40.4)$
\end{tabular}

Have you ever previously reported adverse drug reactions?

Yes

$76(18.7)$

No

330 (81.3)

If you have reported, what type of adverse drug reaction was the most common?a

Serious

42 (55.2)

Rare

$10(13.1)$

Unexpected

$24(31.5)$

Do you think adverse reaction reporting is important and necessary?

Yes

404 (99.5)

No

$2(0.5)$

If your answer is yes, what is the most important reason?

To increase patient safety

To indicate relatively safe drugs

$190(47)$

To determine the incidence of adverse reactions

74 (18.3)

To identify new adverse reactions

$140(34.6)$

${ }^{a} n=76,{ }^{b} n=404$

Table 5. The most important factor that may discourage pharmacists from reporting adverse drug reactions

n (\%)

Lack of time to complete reports

48 (11.8)

Concern that the report will generate extra work

76 (18.7)

Not paying a fee for notification

2 (0.5)

Concern about submitting an inappropriate report

$18(4.4)$

Not knowing how and where spontaneous reporting should be done

150 (36.9)

Incomplete medical history of the patient

$34(8.4)$

The idea that a single spontaneous reporting cannot make a difference

78 (19.2)

Table 6. The most important factor that encourages pharmacists to report adverse drug reactions

n (\%)

Reaction to a new drug

16 (3.9)

Unexpected reaction

$92(22.7)$

Serious reaction

128 (31.5)

Payment asset for instant reporting

$8(2)$

Requiring spontaneous notification

12 (3)

Practical and easy spontaneous reporting process

72 (17.7)

Training of healthcare professionals

78 (19.2) 
In the study, $17 \%$ of pharmacists correctly defined what pharmacovigilance was. This low rate may have resulted from the question being an open-ended question and it was only 3 years ago that the regulation on the pharmacovigilance system (Regulation on Monitoring and Evaluation of the Safety of Medicinal Products for Human Use) came into force. $87 \%$ of pharmacists did not know where to get ADRs reporting forms. ${ }^{14}$ The results of our study showed that the level of knowledge on pharmacovigilance and ADRs reporting increased significantly in Türkiye. This was because pharmacovigilance courses are given in more places during the bachelor's degree. In our study, $40.4 \%$ of pharmacists stated that they had never seen ADRs in their patients, which was a high rate. In the study by Suyagh et al. $^{16}, 8 \%$ of the patients never reported to their pharmacist, when ADRs developed. This might be because patients in Türkiye did not consult pharmacists, when ADRs developed. In the patient information leaflet of some medicines in Türkiye, there is the phrase "consult your doctor when you have an unexpected side effect". This statement may have prevented patients who experienced ADR the pharmacist from consulting, when ADRs develop. Pharmacists should also be added to this statement in the patient information leaflet. Although $99.5 \%$ of the pharmacists thought that ADR reporting was important, $18.7 \%$ of pharmacists previously reported ADRs. This ratio was also supported by other scientific reports that concluded that the rates of ADRs reported by pharmacists in various countries ranged from $14.6 \%$ to $38 \%,{ }^{5,11,15,17-19}$ But this ratio was $7 \%$ in the study by Toklu and Uysal. ${ }^{14}$ This situation demonstrated that the ADR reporting rate has increased in Türkiye.

\section{CONCLUSION}

These results showed that Turkish pharmacists had sufficient knowledge about the concept of pharmacovigilance and the spontaneous ADR reporting system. However, they had little experience in ADRs reporting. Training programs should be ongoing to enhance the role of pharmacists, their knowledge of the reporting process, and requirements and the reporting experience.

\section{Ethics}

Ethics Committee Approval: Ethical approval for this study was obtained from the Gazi University Ethics Committee (approval number and date 2021-445/06.04.2021).

Informed Consent: Informed consent was obtained.

Peer-review: Externally peer-reviewed.

\section{Authorship Contributions}

Concept: A.A., Design: A.A., B.K., Data Collection or Processing: A.A., B.K., Analysis or Interpretation: A.A., B.K., Literature Search: A.A., Writing: A.A., B.K.

Conflict of Interest: No conflict of interest was declared by the authors.

Financial Disclosure: The authors declared that this study received no financial support.

\section{REFERENCES}

1. Classen DC, Pestotnik SL, Evans RS, Lloyd JF, Burke JP. Adverse drug events in hospitalized patients. Excess length of stay, extra costs, and attributable mortality. JAMA. 1997;277:301-306.

2. Pirmohamed M, James S, Meakin S, Green C, Scott AK, Walley TJ, Farrar K, Park BK, Breckenridge AM. Adverse drug reactions as cause of admission to hospital: prospective analysis of 18820 patients. BMJ. 2004;329:15-19.

3. WHO publications. The importance of pharmacovigilance: safety monitoring of medicinal products. WHO Collaborating Centre for International Drug Monitoring, Geneva, Switzerland; 2002. ISBN 92-4159015-7.

4. Balidemaj F. Adverse drug reactions: problems with spontaneous reporting systems and communicating information to providers to improve reporting rate globally. Eur J Public Health. 2017:27.

5. Li R, Curtain C, Bereznicki L, Zaidi STR. Community pharmacists' knowledge and perspectives of reporting adverse drug reactions in Australia: a cross-sectional survey. Int J Clin Pharm. 2018;40:878-889.

6. WHO. Pharmacovigilance: ensuring the safe use of medicines. WHO Policy Perspectives on Medicines, Geneva, Switzerland; 2004. Access date: October 26, 2007. Available from: http://whqlibdoc.who.int/ hq/2004/WHO_EDM_2004.8.pdf

7. Khalili H, Mohebbi N, Hendoiee N, Keshtkar AA, Dashti-Khavidaki S. Improvement of knowledge, attitude and perception of healthcare workers about ADR, a pre-and post-clinical pharmacists' interventional study. BMJ Open. 2012;2:e000367.

8. Rawlins MD. Pharmacovigilance: paradise lost, regained or postponed? The William Withering Lecture 1994. J R Coll Physicians Lond. 1995;29:4149. Erratum in: J R Coll Physicians Lond 1995;29:118.

9. Guidefor the monitorization and evaluation of the medicinal products. Published in the official gazette in $30^{\text {th }}$ March 2005 to become valid by $30^{\text {th }}$ June 2005.

10. Hallit S, Hajj A, Shuhaiber P, Iskandar K, Ramia E, Sacre H, Salameh P; Order of pharmacists of Lebanon scientific committee-Medication safety subcommittee. Medication safety knowledge, attitude, and practice among hospital pharmacists in Lebanon. J Eval Clin Pract. 2019;25:323339.

11. Kopciuch D, Zaprutko T, Paczkowska A, Ratajczak P, ZielińskaTomczak $Ł$, Kus K, Nowakowska E. Safety of medicines-Pharmacists' knowledge, practice, and attitudes toward pharmacovigilance and adverse drug reactions reporting process. Pharmacoepidemiol Drug Saf. 2019;28:1543-1551.

12. Yu YM, Lee E, Koo BS, Jeong KH, Choi KH, Kang LK, Lee MS, Choi KH, Oh JM, Shin WG. Predictive factors of spontaneous reporting of adverse drug reactions among community pharmacists. PLoS One. 2016;11:e0155517.

13. Khan TM. Community pharmacists' knowledge and perceptions about adverse drug reactions and barriers towards their reporting in Eastern region, Alahsa, Saudi Arabia. Ther Adv Drug Saf. 2013;4:45-51.

14. Toklu HZ, Uysal MK. The knowledge and attitude of the Turkish community pharmacists toward pharmacovigilance in the Kadikoy district of Istanbul. Pharm World Sci. 2008;30:556-562.

15. Su C, Ji H, Su Y. Hospital pharmacists' knowledge and opinions regarding adverse drug reaction reporting in Northern China. Pharmacoepidemiol Drug Saf. 2010;19:217-222. 
16. Suyagh M, Farah D, Abu Farha R. Pharmacist's knowledge, practice and attitudes toward pharmacovigilance and adverse drug reactions reporting process. Saudi Pharm J. 2015;23:147-153.

17. Vigneshwaran E, Harichandana V, Sadiq MMJ, Alavudeen SS, Khan NA, Ahmed T. Knowledge, attitude and practice of community pharmacists towards adverse drug reactions reporting. J Young Pharm. 2020;12:75.
18. Vessal G, Mardani Z, Mollai M. Knowledge, attitudes, and perceptions of pharmacists to adverse drug reaction reporting in Iran. Pharm World Sci. 2009;31:183-187.

19. Oreagba IA, Ogunleye OJ, Olayemi SO. The knowledge, perceptions and practice of pharmacovigilance amongst community pharmacists in Lagos state, south west Nigeria. Pharmacoepidemiol Drug Saf. 2011;20:30-35. 